\title{
Analysis of Students’ Out-of-Class Work in Current University Studies
}

\author{
E. Antonino Daviu, D. de Andrés Martínez, A. Palomares Chust, J. C. Ruiz García, \\ C. Gisbert Doménech, A. Peña Cerdán, J. V. Ballester Server, C. Villavieja Llorente
}

Universitat Politècnica de València, Camino de Vera s/n, 46022 Valencia (Spain)

\begin{abstract}
This paper analyses to what extent, and how, student's work can be used to improve students' on-site learning experience and enrich the course evaluation process. The work presented focuses on gathering and analysing different information related to the out-of-class work carried out by students in various Bachelor and Master courses taught at the Universitat Politècnica de València. Results show that there is not a clear relationship between the time devoted to a given task and the attained results, but they highlight especial cases to be considered, like a number of students that devote excessive time to the task but get poor marks. Moreover, the lack of adequate supervision of outof-class work leads to situations where teachers underestimate or overestimate this time. Supervision of student's outof-class work is thus an essential asset for adequately tuning and improving courses content and scheduling, providing meaningful feedback to students, and rewarding the personal work they invest on tasks, something of major importance for keeping students' motivation in continuous learning and evaluation processes.
\end{abstract}

Keywords: Out-of-class work, feedback, analysis, time demands

\section{Introduction}

Within the context of the Bologna Process as director plan for university studies, outof-class work is acquiring a greater relevance in the teaching-learning process. Outof-class work constitutes a fundamental strategy to train and develop students' specific competencies, being also a very useful tool to carry out formative and continuous evaluations (Mohanan, 2005).

Nowadays, the teaching-learning process is not so much oriented to know what and how much the students know, but rather to assess how are they able to use the acquired knowledge in order to interpret and solve realistic problems. This new way of understanding the students' learning process is settled in the theoretical framework known as SAL (Students Approaches to Learning) (Houghton, 2004). The idea is to provide university students with the necessary strategic tools to address the learning process from a more competent perspective, through a metacognitive reflection of learning and study competences (Fry, Ketteridge, \& Marshall, 2014).

Out-of-class work is usually limited to deliver some reports for their subsequent evaluation, but there exist some parameters that cannot be controlled or evaluated with a simple deliverable. For example, the evaluation process could be enriched by knowing how students organize and coordinate their work, which strategies they deploy to reach a solution, how long they need for achieving their objectives, what their opinion about the completed work is, and how they are motivated by the out-ofclass work done. Furthermore, this information would also improve the feedback finally provided to students (Bain, 2004).

The "Tools and Strategies for Competences Assessment" (TASCA) "Innovation and Quality Education Team” (EICE) from the Universitat Politècnica de València (UPV) aims at analysing, applying, and assessing formative and continuous methodologies and strategies to evaluate, in all its dimensions, students' out-of-class work (de Andrés, et al., 2014). The goal is to process all the gathered information to improve and adapt the content of in-class course materials, and increase students' motivation 
and participation in lectures, while providing a more specific and adapted feedback to each student. This will increase the degree of freedom of students over their learning process by allowing them to address their particular weaknesses and reinforce their strengths (Barr \& Tagg, 1995). Figure 1 summarizes the objectives pursued with the analysis of out-of-class work (de Andrés, et al., 2014).

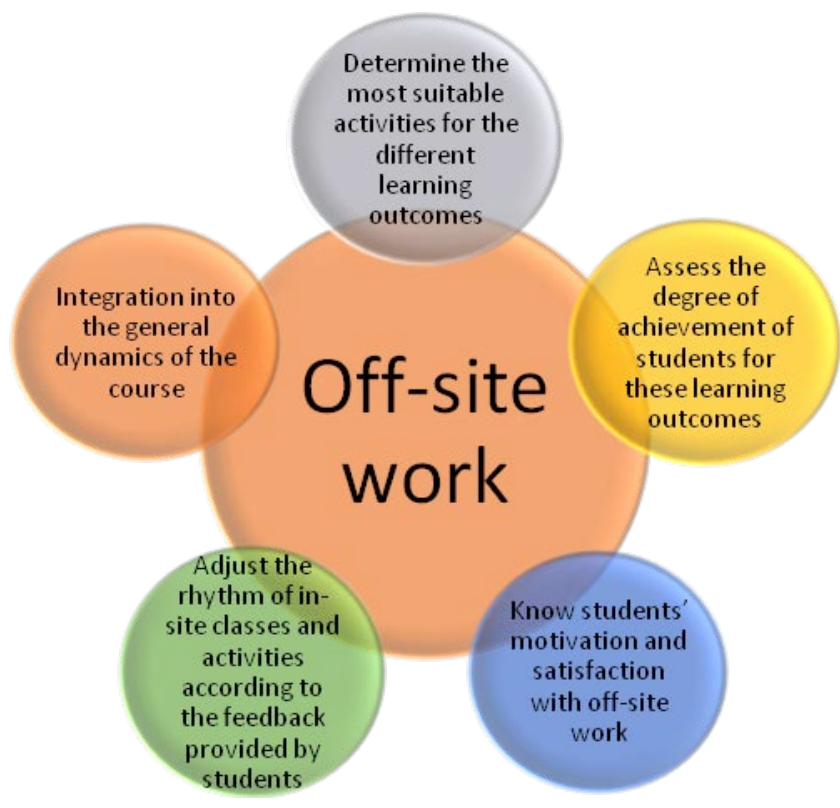

Figure 1. Objectives of out-of-class work analysis.

This paper presents the methodology followed by the TASCA team to obtain and analyse results of out-of-class work activities carried out in different courses, as well as different outcomes resulting from the analysis of questionnaires aimed at collecting students' opinions about out-of-class work. Discussion of the results and conclusions will be presented at the end of the paper.

\section{Method}

The first step consisted in the definition of those questionnaires used to collect and analyse information about out-of-class work. These questionnaires, listed in Table 1, include questions, opinions, and comments about the activity performed and also about the time and effort devoted to such activity, its suitability and usefulness.

They were handed are part of the deliverable of the proposed activities, so information could be quickly gathered in a fluid manner. Students' answers are more reliable when they fill out each questionnaire just after finishing each activity, as their work is recent and they have a clear idea of the whole process that has been followed to address such activity. So these data are very useful to get an immediate and meaningful feedback about out-of-class work.

The second step consisted in the use of these questionnaires after the completion of the out-of-class work. The defined mechanisms for collecting information about students' out-of-class activity have been applied in two semesters. Due to the multidisciplinary nature of the team of teachers conforming TASCA, questionnaires have been adapted according to teachers' criteria, degree, course, kind and duration of the activity. For this study, and as listed in Table 2, courses from different Bachelor and Master's Degrees were considered. Courses have a semester or annual duration 
and in the particular case of the Projects course from the Bachelor's Degree in Architecture, it has students from three different years.

Finally, information collected has been analysed during the third step, taking into account the different kind of proposed activities. Results and discussion are shown in the following section.

Table 1. Analysed out-of-class activities through the associated questionnaires.

\begin{tabular}{|c|c|}
\hline Out-of-class activity & Questionnaire \\
\hline \multirow{4}{*}{$\begin{array}{l}\text { A. Reading a scientific } \\
\text { paper before the } \\
\text { lecture, and answering } \\
\text { a number of relevant } \\
\text { questions. }\end{array}$} & What is the most interesting idea you have learned? Why? \\
\hline & Which question would you like to get answered in the next lecture? Why? \\
\hline & What aspects do not require further explanation after reading the paper? \\
\hline & How long did it take you to read the paper and answer these questions? \\
\hline \multirow{5}{*}{$\begin{array}{l}\text { B. Applying the } \\
\text { contents of a lecture to } \\
\text { students' projects. }\end{array}$} & Is the main concept of the lecture clear? Do you have any doubts? \\
\hline & Have you found it difficult to apply it to your project? Why? \\
\hline & Has this exercise helped you in clarifying the main lecture's concepts? \\
\hline & Which new questions or doubts do you have after making this exercise? \\
\hline & How long did it take you to review the lecture and make the exercise? \\
\hline \multirow{5}{*}{$\begin{array}{l}\text { C. Searching a paper, } \\
\text { extracting information } \\
\text { as shown in lectures, } \\
\text { and preparing a } \\
\text { presentation about the } \\
\text { paper's contents. }\end{array}$} & How long did it take you to select the paper? \\
\hline & Was it difficult to comprehend and extract the information? Why? \\
\hline & What is the conclusion of the paper? \\
\hline & Have you acquired new competencies and/or knowledge? \\
\hline & How long did it take you to work on the paper and presentation? \\
\hline \multirow{3}{*}{$\begin{array}{l}\text { D. Solving long } \\
\text { problems about the } \\
\text { content of some } \\
\text { lectures. }\end{array}$} & How long did it take you to solve the problem? \\
\hline & Did it allow you to review and better understand the lectures’ contents? \\
\hline & Do you have questions or doubts about the content of the exercise? \\
\hline
\end{tabular}

\section{Results and Discussion}

The first problem faced during this work was the difficulty in making all students to answer the questionnaire. Even although it was handed as part of the deliverable, as commented before, some students refused to answer it. Moreover, in courses were out-of-class work was optional, some students even declined to present the work.

Figure 3 shows an example of two courses taught in our Bachelor of Telecommunications, the "Telecommunications Networks and Systems II" course (TNS2) with two proposed exercises (Figure 3a and Figure 3b) and the "Propagation" course (Figure 3c). As observed, optional out-of-class work was only performed by around $80 \%$ of the students. From these students, a $73 \%$ completed the questionnaire about exercise I of TNS2, 88\% about exercise II of TNS2 and 91\% answered the questionnaire about the problem in "Propagation" course. In this last case, participation in the questionnaire was rewarded with some extra points ( 0.25 points over 10) in the mark, which may justify the observed higher participation. 
Table 2. List of target courses.

\begin{tabular}{|c|c|c|}
\hline $\begin{array}{l}\text { Out-of-class } \\
\text { activity }\end{array}$ & Degree & Course \\
\hline \multirow{2}{*}{ A } & $\begin{array}{l}\text { Bachelor's Degree in } \\
\text { Informatics Engineering }\end{array}$ & Design of digital systems \\
\hline & $\begin{array}{l}\text { Master's Degree in Computer } \\
\text { and Network Engineering }\end{array}$ & Design of architectures in VLSI \\
\hline B & $\begin{array}{l}\text { Bachelor's Degree in } \\
\text { Architecture }\end{array}$ & Projects \\
\hline \multirow{2}{*}{$\mathrm{C}$} & $\begin{array}{l}\text { Bachelor's Degree in } \\
\text { Biotechnology }\end{array}$ & $\begin{array}{l}\text { In vitro culture and genetic transformation of } \\
\text { plants }\end{array}$ \\
\hline & $\begin{array}{l}\text { Master's Degree in Plant } \\
\text { Genetics and Breeding }\end{array}$ & $\begin{array}{l}\text { Application of in vitro culture to plant } \\
\text { improvement }\end{array}$ \\
\hline \multirow{2}{*}{$\mathrm{D}$} & \multirow{2}{*}{$\begin{array}{l}\text { Bachelor's Degree in } \\
\text { Telecommunications } \\
\text { Systems, Sound and Image } \\
\text { Engineering }\end{array}$} & Propagation \\
\hline & & Telecommunication Networks and Systems II \\
\hline
\end{tabular}

Telecommunications Networks and Systems II: Exercise 1

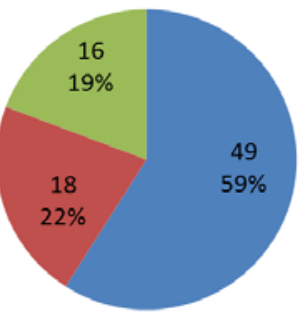

- Problem done and participate

- Problem done but don't participate

Problem not done

(a)

Telecommunications Networks and Systems II: Exercise 2

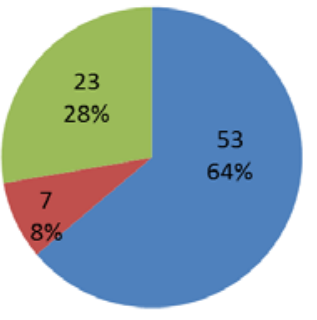

Problem done and participate

- Problem done but don't participate

- Problem not done

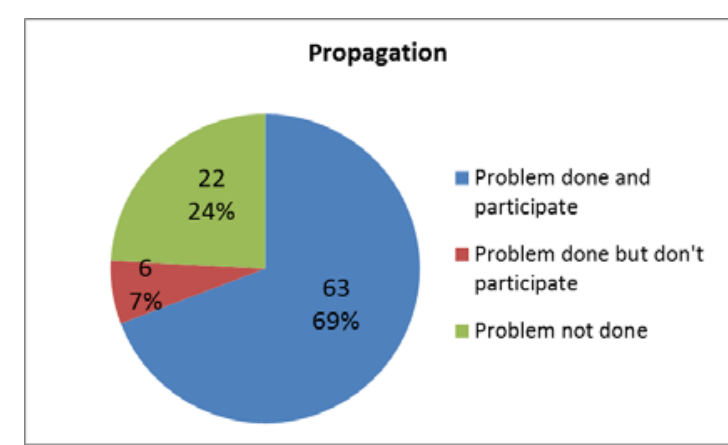

(c)

Figure 3.Participation in out-of-class work and questionnaires.

One of the questions formulated in all questionnaires was about the time students' devoted to out-of-class work. In Figure 4 the cumulative distributed function (CDF) of students having finished the activity in a given time is presented for different target 
courses. The red line in the graphs represents the time expected by the teacher to complete the out-of-class activity.

Through this type of graph it is possible to estimate whether the teacher has underestimated the time required to finish the out-of-class activity or, on the contrary, students' needed less time that expected to finish the task. As observed, in Figure 4a less than $75 \%$ of students finished in the expected time, less than $50 \%$ in Figure $4 \mathrm{~b}$, and less than $30 \%$ in Figure 4c. This shows that, mostly at the third case, time estimated by the teacher was too short, which has helped to re-adjust the duration of the exercise and workload for successive proposals of this activity.

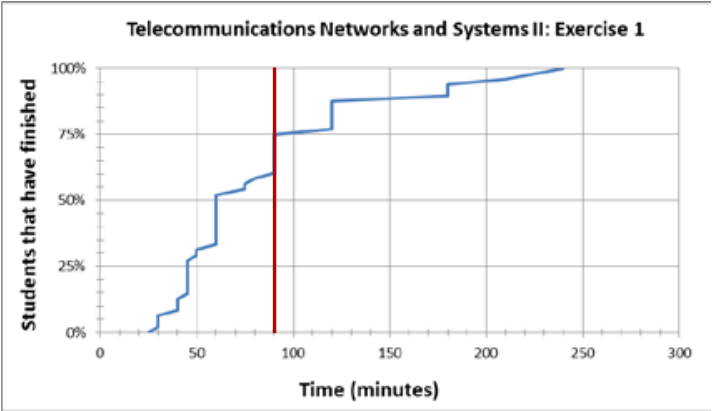

(a)

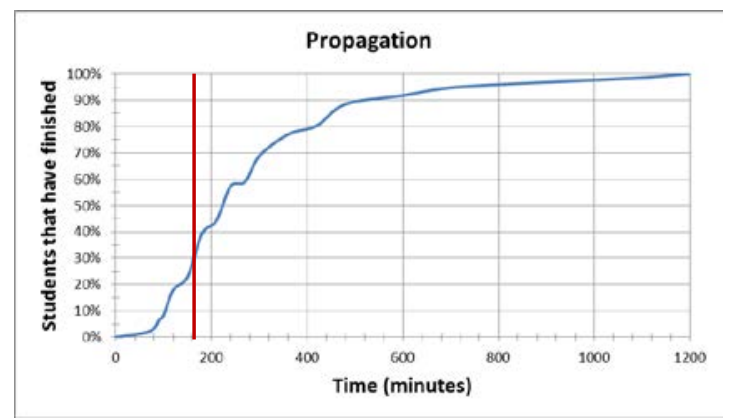

(c)

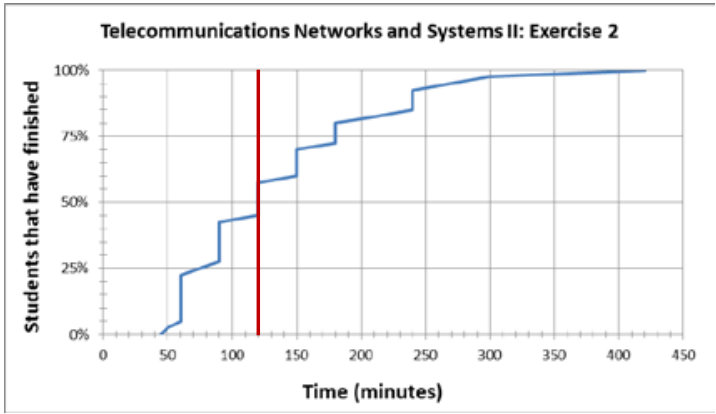

(b)

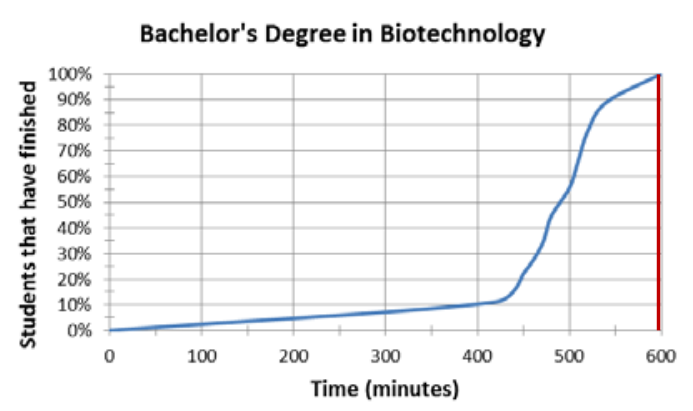

(d)

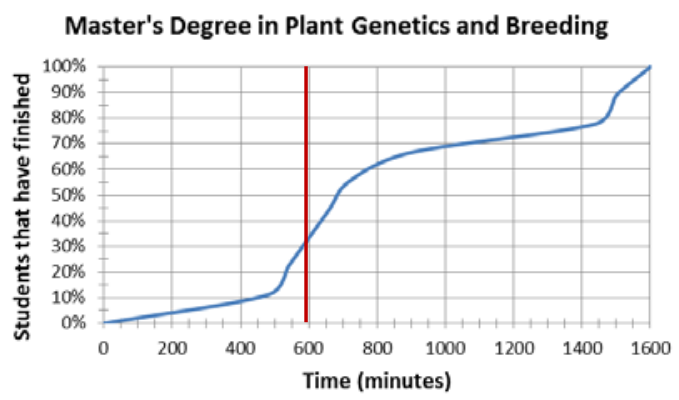

(e)

Figure 4.Cumulative distributed function of students having finished the activity in a given time, for different courses.

The same activity was proposed in the "Bachelor's Degree in Biotechnology" (Figure 4d) and the "Master's Degree in Plant Genetics and Breeding" (Figure 4e). As can be seen, all students from the "Bachelor's Degree in Biotechnology" finished the activity before the estimated time. Nevertheless, it seems that the task is not too easy either, as barely any student completed the deliverable in less than 450 minutes. In the case of master students just about $30 \%$ of them finished the task in that time. In fact, twice 
that time was required for $75 \%$ of students to finish the activity. This clearly points out a problem that could be related to the heterogeneity of students enrolled in the master course, whereas degree students have a more homogenous profile that better fits the task at hand. Probably, it could be a good idea to complement the task for master students with a previous lecture or activity for them to acquire a homogeneous knowledge.

By progressively repeating this kind of approach in successive years we expect to properly adjust the workload and duration of each considered activity, and probably introduce new activities or remove some of them, according to ECTS-based requirements and observed students’ performance.

Figure 5 shows the grades obtained by students in the out-of-class activities previously explained. Grades are represented with respect to the time required by the student to complete the task. This will help us to determine whether there is any relationship between the time devoted to the task and the marks finally obtained. It is worth mentioning that the Spanish grading system uses a 10-based scale, where 10 is the maximum grade and the student fails if his/her grade is lower than 5 .

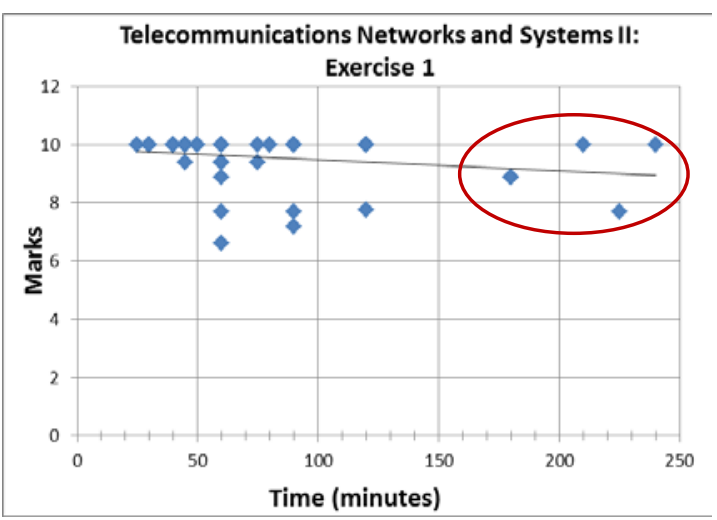

(a)

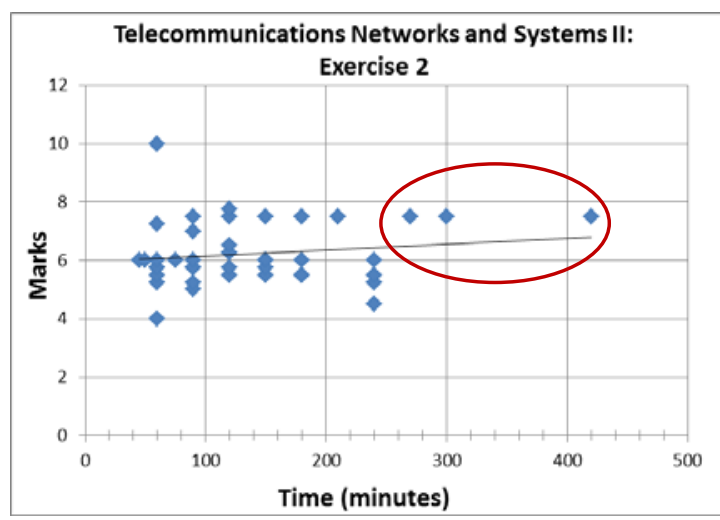

(b)

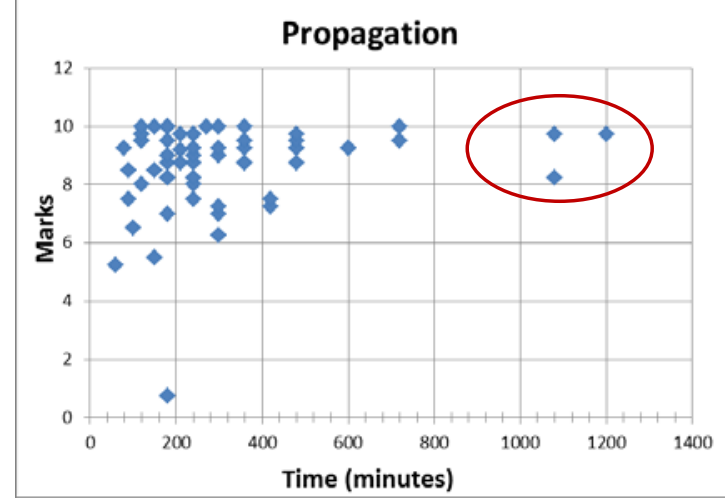

(c) 


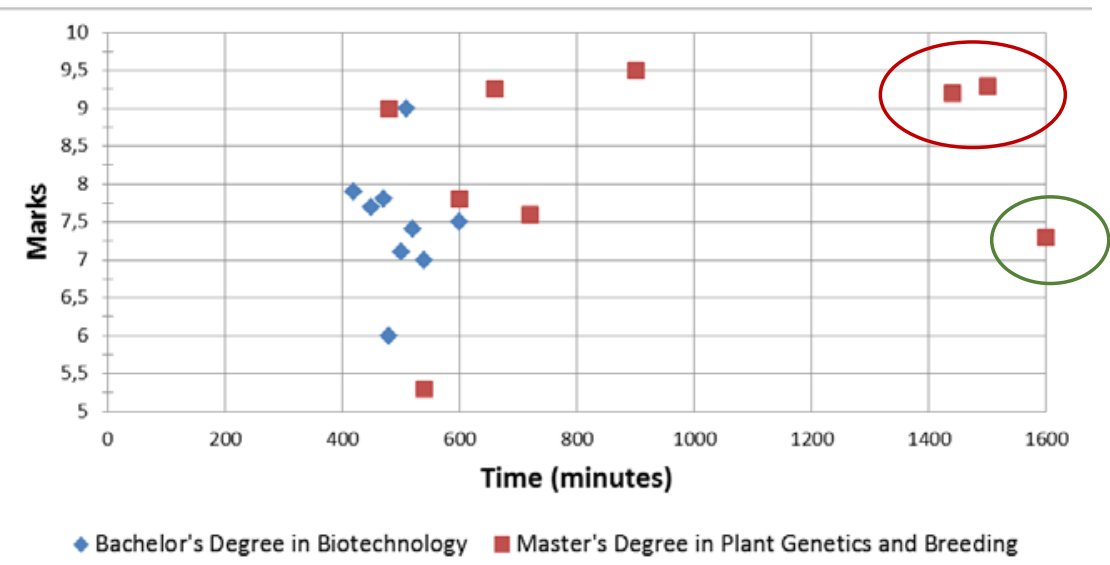

(d)

Figure 5.Relationship between marks assigned and time devoted to the task.

The first thing to be noted is that it does not seem to be any clear relationship between the assigned marks and the time devoted to the task. There exist, in all courses, high grades for deliverables declaring relatively low dedication, and low grades for deliverables that reported a long time to complete.

However, with this kind of graph it is easier to detect possible problems. For instance, the case of students employing much more time than the rest to finish the task (highlighted with a red circle in Figure 5) and students reporting the longest time devoted to the task and achieving low mark (highlighted with a green circle in Figure 5). These cases could probably point out some difficulties with the content of related lectures, for instance, and a meeting with these students for clarification and guidance may be necessary. The early detection of recurring cases is of prime importance to be able to help students with learning or organisational problems, possibly redirecting them to the UPV's Institute of Education Sciences (ICE) where specially trained staff may attend their necessities.

\section{Conclusions}

The progressive integration of out-of-class work assessment in the courses' dynamics could become a basic tool in the teaching-learning process. On the one hand, the assessment of out-of-class work does not limit its scope to the delivered final result, but also to its development process and the student progress, leading to fairer and more objective evaluation. On the other hand, feedback of prime importance is obtained regarding students' satisfaction with activities and courses, their strengths and weaknesses, which can be used to improve the scheduling, scope, and structure of out-of-class activities and the organisation of the course in general.

In spite of the heterogeneity of degrees, courses, and activities considered by TASCA team members, obtained data have constituted a key tool to detect opportunities and menaces in the deployed teaching-learning process. Reliable information about the ongoing progression of students, both individually and as a group, enables the early detection of learning problems that teachers may tackled by deploying appropriated countermeasures.

The steady use of these kinds of questionnaires also enables students themselves to reflect about their own learning process, so they have the possibility of changing their work and study methods to improve their performance and efficiency. 
The future work of the TASCA team aims at deploying that kind of approach on a large scale in all out-of-class activities defined for the considered courses, fine tuning the proposed questionnaires to find a single pattern that could match all kind of activities, and verifying that the potential benefits of this approach by direct observation and comparison with previous years results.

\section{Acknowledgement}

This work has been sponsored by Universitat Politècnica de Valencia's projects PIME 008-A-2013 and PIME/2014/A/022/A.

\section{References}

Bain, K. (2004). What the Best College Teachers Do. Harvard University Press.

Barr, R., \& Tagg, G. J. (1995). From teaching to learning - A new paradigm in undergraduate education. Change, 27(6), 13-15.

de Andrés, D., Ruiz, J., Antonino, E., Palomares, A., Gisbert, C., Peña, A., Villavieja, C. (2014). Towards integrating mechanisms to assess students' off-site work within the regular teaching-learning process. International Conference of Education Research and Innovation, (pp. 3025-3034). Seville, Spain.

Fry, H., Ketteridge, S., \& Marshall, S. (2014). A Handbook for Teaching and Learning in Higher Education: Enhancing academic practice (4th ed.). Routledge.

Houghton, W. (2004). Engineering Subject Centre Guide: learning and teaching theory for engineering academics. (L. Willis, Ed.) Higher Education Academy Engineering Subject Centre, Loughborough University.

Mohanan, K. P. (2005). Assessing Quality of Teaching in Higher Education. Retrieved from Centre for Development of Teaching and Learning: http://www.cdtl.nus.edu.sg/publications/assess/default.htm 